\title{
Low vision in east African blind school students: need for optical low vision services
}

\author{
Janet Silver, Clare E Gilbert, Peter Spoerer, Allen Foster
}

Department of

Preventive

Ophthalmology,

Institute of

Ophthalmology,

London

C E Gilbert

A Foster

Christoffel

Blindenmission, East

Africa Regional Office,

PO Box 58004,

Nairobi, Kenya

P Spoerer

Visual Assessment

Department,

Moorfields Eye

Hospital, London

J Silver

Correspondence to:

Janet Silver, Visual

Assessment Department,

Moorfields Eye Hospital,

City Road, London EC1V

2PD.

Accepted for publication

17 May 1995

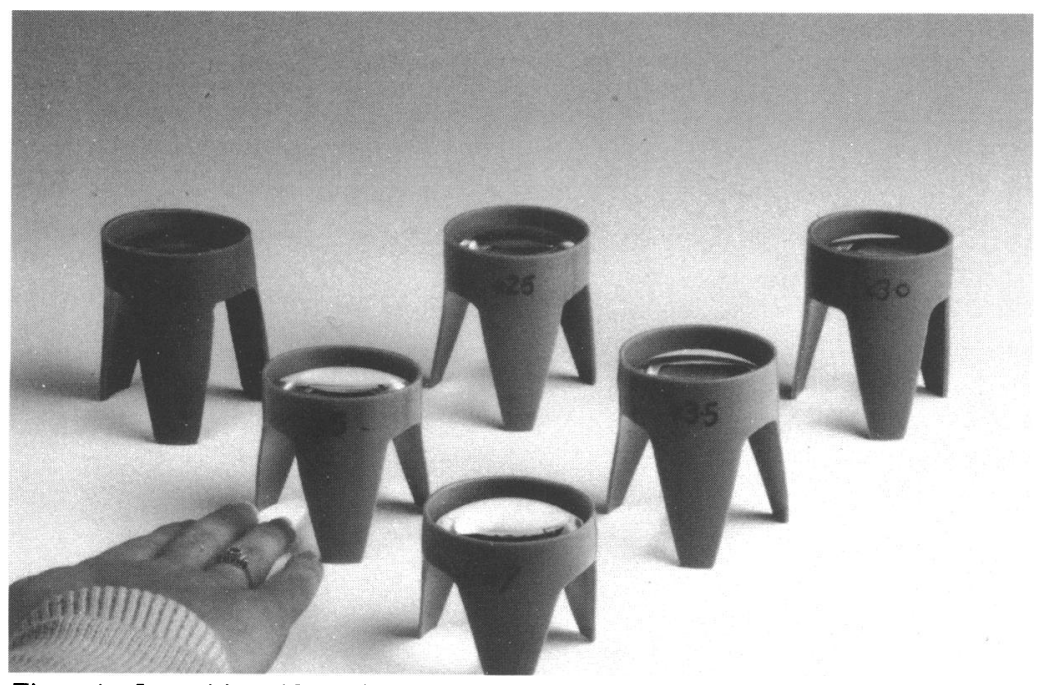

Figure 1 Low vision aids produced in the optical workshop in Nairobi.

\begin{abstract}
Aims-There is increasing awareness of the needs of children with low vision, particularly in developing countries where programmes of integrated education are being developed. However, appropriate low vision services are usually not available or affordable. The aims of this study were, firstly, to assess the need for spectacles and optical low vision devices in students with low vision in schools for the blind in Kenya and Uganda; secondly, to evaluate inexpensive locally produced low vision devices; and, finally, to evaluate simple methods of identifying those low vision students who could read N5 to N8 print after low vision assessment.

Methods-A total of 230 students were examined (51 school and 16 university students in Uganda and 163 students in Kenya, aged 5-22 years), 147 of whom had a visual acuity of less than $6 / 18$ to perception of light in the better eye at presentation. After refraction seven of the 147 achieved $6 / 18$ or better. Eighty two $(58.6 \%)$ of the 140 students with low vision (corrected visual acuity in the better eye of less than 6/18 to light perception) had refractive errors of more than 2 dioptres in the better eye, and $38(27 \cdot 1 \%)$ had more than 2 dioptres of astigmatism.

Results-Forty six per cent of students with low vision $(n=64)$ could read N5-N8 print unaided or with spectacles, as could a further $33 \% \quad(n=46)$ with low vision devices. Low vision devices were indicated in a total of 50 students $(35 \cdot 7 \%)$. The locally manufactured devices could meet two thirds of the need.
\end{abstract}

In many developing countries children with visual disability are taught in residential schools. This is particularly true in Africa, where programmes of integrated education are still being developed. A significant proportion of students in schools for the blind in Africa are severely visually impaired rather than blind, but despite this most formal education is conducted using techniques appropriate for the totally blind such as braille. There is, however, increasing awareness of the needs of children with low vision and some countries are now developing educational services for students with low vision. ${ }^{12}$ Being able to read ink print allows a child much greater access to information and a wider range of recreational activities and educational and employment opportunities. For children with low vision optical devices may be required to attain a near acuity which allows access to ink print.

Until recently the World Health Organisation's (WHO) category of low vision was a corrected acuity in the better eye of less than $6 / 60$ to $3 / 60$. However, this definition is restrictive, as many individuals who have acuities of less than $3 / 60$ to light perception in the better eye have useful vision. The following definition of low vision has recently been agreed by WHO:

'A person with low vision is one who has impairment of visual function even after treatment and/or refractive correction, and has a visual acuity in the better eye of less than $6 / 18$ to light perception, or a visual field of less than $10^{\circ}$ from the point of fixation, but who uses or is potentially able to use vision for the planning or execution of a task.'

Christoffel Blindenmission (CBM) a nongovernmental development organisation involved in prevention of blindness programmes throughout the developing world, also provides support for children in schools for the blind. CBM promotes optical workshops which produce low cost spectacles. ${ }^{3}$ A range of low vision devices (LVDs) has been developed at the optical workshop near Nairobi (Fig 1). The devices are robust and 
inexpensive, but had not been field tested, and it was not known how well the range and design would meet the needs of children with low vision.

The aims and objectives of the study were as follows:

(1) to determine the range of refractive errors and need for distance spectacles in students with low vision in schools for the blind in east Africa;

(2) to determine the proportion of students with low vision who have the potential to discern N5-N8 or N10-N36 print after accurate refraction and assessment with LVDs;

(3) to determine from a range of LVDs that meet British and international standards the type of devices required, and the feasibility of creating a smaller range that would be helpful to the majority of students who have the potential to benefit;

(4) to determine to what extent the locally produced (CBM) LVDs could meet the need;

(5) to evaluate simple methods which could be used by teachers and others to identify students who would benefit from low vision assessment.

The requirements for distance LVDs, such as telescopes, were not assessed in this study, as these have more limited applications than those for near work, are more difficult to manufacture, and are expensive to purchase.

\section{CALCULATION OF MAGNIFICATION}

Magnification, or rather how it is calculated, is a complex area as the optical system of the eye as well as the power of the LVD being used have to be taken into consideration. Standard calculations are based on the equivalent power of the lens(es). Two formulas are commonly used for calculating the magnification of stand and hand held devices; $M=f / 4$ (formula 1 ), where $f=$ the focal length of the lens of the LVD in dioptres (D). This is the standard formula in the USA, and is widely used by clinicians. However, the formula $M=f / 4+1$ (formula 2) has been promoted by certain manufacturers, and is now generally used by them. The British Standards Institution calls the latter 'trade magnification' and to avoid confusion they recommend that all magnifiers are labelled with the equivalent power (D). ${ }^{4}$ To further complicate the issue, if the lens is placed closer to the object than its focal length then its effective magnification is reduced and an accommodative effort (or an appropriate near add) is required to compensate for the divergence of the emergent rays. The magnification of spectacle magnifiers (hyperoculars) can also be calculated using either formula, but the more frequently used is $M=f / 4$, which assumes that the material will be placed at the far point.

The reading distance and, hence, size of the image falling on the retina will also be influenced by the refractive error of the user. For example, when using formula 1 , a $\times 5$ labelled lens (that is, $+20 \mathrm{D}$ ) in an uncorrected high myope who normally uses $-12 \mathrm{D}$, will have a total optical system of $32 \mathrm{D}(+12 \mathrm{D}$ of his own $+20 \mathrm{D}$ from the hyperocular). The working distance will be $3.3 \mathrm{~cm}(100 / 32)$ and the magnification $\times 8$ (using $\mathrm{f} / 4$ ). If the user is aphakic, normally needing $+12 \mathrm{D}$, the same hyperocular lens will produce only $\times 2$ magnification and the working distance will be $12.5 \mathrm{~cm}$ ( +20 from the hyperocular $-12 \mathrm{D}$ to correct the aphakia $=8 \mathrm{D} ; M=8 / 4=\times 2$; working distance $=100 / 8=12 \cdot 5 \mathrm{~cm}$ ).

In an emmetropic eye $4 \mathrm{D}$ of accommodation (or reading add) is required to focus print at $25 \mathrm{~cm}$. If the print is moved from $25 \mathrm{~cm}$ to $12.5 \mathrm{~cm}$ the angle subtended at the eye will increase by a factor of $\times 2$ with a corresponding increase in image size. An emmetropic eye will need $+8 \mathrm{D}$ to focus the image while an uncorrected highly short sighted (myopic) eye of $-12 \mathrm{D}$ will need $-4 \mathrm{D}$, and an aphakic eye might need $(+20 \mathrm{D})$. The actual retinal image size will be very similar for each individual. However, variations are caused by the effects of back vertex distance (BVD) and thick lens optics, but with lenses of $20 \mathrm{D}$ or less variations in image size are rarely as much as $10 \% .^{5}$

In this study, in order to simplify the calculation of magnification required by students the principles outlined above have been used, and the reciprocal of the reading distance calculated as a measure of magnification at the eye irrespective of the type of optical correction or the power of LVD required. Young people are able to bring print very close, using accommodation to provide magnification, but as this effort is unlikely to be sustainable LVDs may be indicated for prolonged close work.

\section{MEASUREMENT OF NEAR VISION}

Snellen charts (or their equivalent) are constructed so that each element of the 6 metre figure subtends 1 minute of arc at the retina of the viewer, the whole character subtending 5 minutes. The Faculty of Ophthalmologists' ' $N$ series' of reading charts, which uses printer's type faces, is constructed so that there is an arithmetic relation between the different sizes of print. ${ }^{6}$ On the basis of visual angle subtended at the eye it is possible to correlate distance and near measurements of visual acuity. For example, a distance acuity of $6 / 18$ is equivalent to $\mathrm{N} 5$ at $25 \mathrm{~cm}$, as both subtend the same visual angle.

The print size used in books for students is not standardised. For the purpose of this study near acuity was banded into two groups; N5 to N8, which would allow access to most printed materials, and N10 to N36 which would allow only limited access to ink print.

\section{Materials, subjects, and methods}

\section{MATERIALS}

The Sonksen-Silver visual acuity test (S-S) was used during refraction and low vision assessments. This test, which is based on Snellen acuities and which uses multiple optotypes at every level, allows measurement of distance visual acuity at any distance, can be used as a matching test, and can be used to measure near visual acuity. The S-S test has the advantage of 
Table 1 Grouping of students after assessment for near vision

\begin{tabular}{|c|c|c|}
\hline Group & $\begin{array}{l}\text { Print size read/ } \\
\text { discerned }\end{array}$ & Optical device required \\
\hline $\begin{array}{l}1 \\
2 \\
3 \\
4 \\
5 \\
6 \\
7\end{array}$ & $\begin{array}{l}\text { N5-N8 } \\
\text { N5-N8 } \\
\text { N5-N8 } \\
\text { N10-N36 } \\
\text { N10-N36 } \\
\text { N10-N36 } \\
\text { N48 or less }\end{array}$ & $\begin{array}{l} \pm \text { Own spectacles } \\
\text { With new corrective lenses } \\
\text { With LVD } \\
\pm \text { Own spectacles } \\
\text { With new corrective lenses } \\
\text { With LVD } \\
\text { With any optical device }\end{array}$ \\
\hline
\end{tabular}

being light, portable, and readily understandable without the benefit of a common language. Matching can be used for individuals who do not speak English or who cannot read. Snellen acuities rather than logarithm based acuities were used in this study as the WHO categories of visual loss are based on Snellen acuities.

Low vision devices (stand and hand held magnifiers, and hyperoculars) made by Combined Optical Industries were used during the low vision assessment. Simple magnifiers are readily available, relatively inexpensive, do not require skilled dispensing, and have been shown to be well accepted by children. ${ }^{7}$ The COIL magnifiers are made using acrylic, aspheric lenses. In the stand magnifiers the lenses are mounted in a horseshoe-shaped stand so that the emergent rays are parallel (except for the $76 \mathrm{D}$ which allows a little focusing). The stand magnifiers used in the assessment provided the greatest range of available powers $(8,12,20,28,36,44,56$, and 76 dioptres). Hand held magnifiers of 3, 6, 12, and 20 dioptres and hyperoculars (spectacle magnifiers with surface curvatures calculated to reduce aberrations) in powers of $12,16,20$, $24,32,40$, and 48 dioptres were also used. The magnifiers are fully described in the manufacturer's material and the literature. ${ }^{89}$

The optical aids produced by CBM are produced from locally available materials, and can be made by people with little previous experience or knowledge, after a short period of training. ${ }^{3}$ With appropriate technology it is possible to manufacture stand and hand held magnifiers, aphakic spectacles, and simple galilean telescopes. The stands are made from plastic drainpipe and the lenses are ground from window glass. The lens diameter is approximately $50 \mathrm{~mm}$. In the higher powers there is little or no divergence as the stand places the lens close to its focal length. In the lower power magnifiers the stands are relatively short, and demand either accommodation, a near correction, or that the magnifier is lifted off the page. Because each magnifier is

Table 2 Categories of visual loss before and after refraction (corrected acuity in the better eye) in 230 students in schools for the blind in Kenya and Uganda

\begin{tabular}{|c|c|c|c|c|c|}
\hline \multirow[b]{2}{*}{ WHO categories } & \multirow[b]{2}{*}{ Visual loss } & \multicolumn{2}{|c|}{ Before refraction } & \multicolumn{2}{|c|}{ After refraction } \\
\hline & & $N$ & $\%$ & $N$ & $\%$ \\
\hline $\begin{array}{l}\text { No impairment } \\
\text { Low vision }\end{array}$ & $6 / 6-6 / 18$ & 14 & $6 \cdot 1$ & 21 & $9 \cdot 1$ \\
\hline $\begin{array}{l}\text { VI } \\
\text { SVI } \\
\text { Blind } \\
\text { Totally blind }\end{array}$ & $\begin{array}{l}<6 / 18-6 / 60 \\
<6 / 60-3 / 60 \\
<3 / 60-\text { PL } \\
\text { NPL }\end{array}$ & $\begin{array}{l}34 \\
53 \\
60 \\
69\end{array}$ & $\begin{array}{l}14 \cdot 8 \\
23 \cdot 0 \\
26 \cdot 1 \\
30 \cdot 0\end{array}$ & $\begin{array}{l}50 \\
48 \\
42 \\
69\end{array}$ & $\begin{array}{l}21 \cdot 7 \\
20 \cdot 9 \\
18 \cdot 3 \\
30 \cdot 0\end{array}$ \\
\hline Total & & 230 & 100 & 230 & 100 \\
\hline
\end{tabular}

$\mathrm{VI}=$ visual impairment; $\mathrm{SVI}=$ severe visual impairment made individually, there will be small differences at the same nominal power. Locally produced stand magnifiers of $8,10,12,16,20$, and 28 dioptres (the highest power available) were used in this study.

\section{SUBJECTS}

In Uganda 51 pupils from two schools for the blind were examined as well as 16 university students. In Kenya 163 pupils from three schools for the blind were examined. All pupils in the Ugandan schools were examined, but this was not possible in Kenya as the schools were much larger. In order to obtain a representative sample of students, classes were selected from all age groups and all students in those classes were examined.

\section{METHODS}

Distance visual acuities were measured in each eye separately using a Snellen E chart, with spectacles if normally worn. Visual fields were assessed by confrontation when indicated. Students with a visual acuity less than $6 / 18$ to light perception in the better eye underwent three simple, recently developed tests of functional vision ${ }^{10}$ and were assessed by the optometrist.

\section{Tests of functional vision}

Three simple tests of functional vision were undertaken to determine whether the student had useful residual vision for:

(1) independent mobility (that is, ability to navigate without assistance between two chairs, set 2 metres apart, in a well lit room)

(2) social contact (that is, ability to recognise someone known to them at a distance of 2 metres)

(3) near vision (that is, ability to recognise or describe the shape of three $5 \mathrm{~mm}$ symbols at any near distance).

\section{Low vision assessment}

Distance visual acuity measurement was repeated using the $S-S$ test. Near visual acuities were measured in each eye using $\mathbf{N}$ series test types, with spectacles if these were available. The S-S near chart was used for students unable to read ink print. The reading distance was recorded for the better eye. Refraction was performed using standard techniques through an undilated pupil. The best corrected distance and near acuities, the refractive error and the eye to near chart distance were recorded for the better eye.

All students unable to read N5 to N8 before or after refraction were then assessed with the LVDs from the UK, using the better eye. The level of near acuity achieved, the reading distance, and the type and power of the LVD were recorded. All students who benefited from the British devices were then assessed using the CBM LVDs.

After assessment the students were grouped as shown in Table 1. The prescriptions and 
Table 3 Refractive errors in 147 students with low vision at presentation in schools for the blind in Kenya and Uganda (spherical equivalents)

\begin{tabular}{|c|c|c|c|c|}
\hline \multirow[b]{2}{*}{ Refractive error (D) } & \multicolumn{2}{|c|}{$\geqslant 6 / 18$ After refraction ${ }^{\star}$} & \multicolumn{2}{|c|}{$<6 / 18$ To LP after refraction $\dagger$} \\
\hline & $N$ & $\%$ & $N$ & $\%$ \\
\hline $\begin{array}{l}0-2 \cdot 0 \\
2 \cdot 25-5 \cdot 0 \\
5 \cdot 25-8 \cdot 0 \\
8 \cdot 25-11 \cdot 0 \\
11 \cdot 25 \text { or more } \\
\text { Refraction not possible }\end{array}$ & $\begin{array}{l}3 \\
2 \\
0 \\
0 \\
2 \\
0\end{array}$ & $\begin{array}{c}43 \cdot 0 \\
28 \cdot 5 \\
0 \\
0 \\
28 \cdot 5 \\
0\end{array}$ & $\begin{array}{r}38 \\
37 \\
9 \\
10 \\
26 \\
20\end{array}$ & $\begin{array}{r}27 \cdot 0 \\
26 \cdot 4 \\
6 \cdot 4 \\
7 \cdot 2 \\
18 \cdot 6 \\
14 \cdot 4\end{array}$ \\
\hline Total & 7 & 100 & 140 & 100 \\
\hline Significant cylinder $(>2)$ & 3 & $42 \cdot 9$ & 35 & $25 \cdot 0$ \\
\hline
\end{tabular}

«No impairment after refraction. †Low vision according to the new definition after refraction.

names of students and who would benefit from spectacles or LVDs were given to the principals of the schools and the attending ophthalmologists.

\section{Results}

\section{CATEGORIES OF VISUAL LOSS}

A total of 230 students was examined. Levels of visual loss were recorded according to WHO categories and are shown in Table 2. At presentation $14(6 \cdot 1 \%)$ students had no visual impairment. Thirty four students had visual impairment $(<6 / 18-6 / 60)$ and 53 were severely visually impairment $(<6 / 60-3 / 60)$. Sixty students had vision in the range of less than $3 / 60$ to light perception in the better eye (blind) and 69 students had no perception of light in both eyes (totally blind). After refraction the visual acuity in the better eye improved by one or more categories in 46 students $(20 \%)$.

Of the 230 students included in the study, $140(61 \%)$ were classified as having low vision, according to the new definition. Forty two $(30 \%)$ of the 140 students with low vision were blind according to WHO categories of visual loss. The ages of individuals with low vision ranged from 5-22 years (mean 13.6 years). Forty two were aged over 15 years at the time of the study, but all had developed visual loss before the age of 16 years and so have been included. Eighty nine $(64 \%)$ were male.

REFRACTIVE ERRORS IN STUDENTS WITH LOW VISION

Students with normal vision at presentation

Table 4 Near visual acuity after assessment in 140 students in Kenya and Uganda

\begin{tabular}{|c|c|c|c|c|c|c|}
\hline \multirow[b]{2}{*}{ Group } & \multirow{2}{*}{$\begin{array}{l}\text { Print size read/ } \\
\text { discerned }\end{array}$} & \multirow[b]{2}{*}{ Optical device required } & \multirow[b]{2}{*}{$N$} & \multirow[b]{2}{*}{$\%$} & \multicolumn{2}{|c|}{ Subtotal } \\
\hline & & & & & $N$ & $\%$ \\
\hline $\begin{array}{l}1 \\
2 \\
3\end{array}$ & $\begin{array}{l}\text { N5-N8 } \\
\text { N5-N8 } \\
\text { N5-N8 }\end{array}$ & $\begin{array}{l} \pm \text { Own spectacles } \\
\text { With new correction } \\
\text { With LVD }\end{array}$ & $\begin{array}{r}56 \\
8 \\
46\end{array}$ & $\begin{array}{r}40 \cdot 0 \\
5 \cdot 7 \\
32 \cdot 9\end{array}$ & & \\
\hline $\begin{array}{l}4 \\
5 \\
6\end{array}$ & $\begin{array}{l}\text { N10-N36 } \\
\text { N10-N36 } \\
\text { N10-N36 }\end{array}$ & $\begin{array}{l} \pm \text { Own spectacles } \\
\text { With new correction } \\
\text { With LVD }\end{array}$ & $\begin{array}{l}7 \\
2 \\
3\end{array}$ & $\begin{array}{c}5 \cdot 0 \\
14 \\
2 \cdot 2\end{array}$ & 110 & 100 \\
\hline 7 & $\begin{array}{l}\text { N48 } \\
\text { N48 } \\
\text { Less than N48 }\end{array}$ & $\begin{array}{l} \pm \text { Own spectacles } \\
\text { With LVD } \\
\text { With any device }\end{array}$ & $\begin{array}{r}1 \\
1 \\
16\end{array}$ & $\begin{array}{r}0.7 \\
0.7 \\
11 \cdot 4\end{array}$ & 18 & $12 \cdot 8$ \\
\hline Total & & & 140 & 100 & 140 & 100 \\
\hline
\end{tabular}

(14) and those who could not see light in either eye (69) were not refracted. In a further 20 students refraction was not possible because of very low acuity combined with dense media opacity. Findings of refraction are presented in Table 3. Eighty two of the 140 students with low vision had refractive errors of more than 2 dioptres $(58 \cdot 6 \%)$ and 35 had astigmatism of $2 \mathrm{D}$ or more $(25.0 \%)$. Corrective lenses improved the visual acuity in the better eye in 59 students; by one line in 37 , two lines in 17 , and three or more lines in five students.

Forty six students with low vision needed spectacles and in the remaining 13 the improvement in acuity was not sufficient to warrant spectacle correction. At presentation 28 students were already wearing spectacles, but in 13 the visual acuity could be improved with a change in prescription.

\section{NEAR VISUAL ACUITY AFTER LOW VISION}

ASSESSMENT

One hundred and ten $(78 \cdot 6 \%)$ students with low vision were able to discern N5 or N8 print with or without optical devices (Table 4). A further 12 students $(8.6 \%)$ could discern N10-N36 print. Two students could discern N48 print and 16 were unable to discern even the largest print.

\section{LOW VISION DEVICES REQUIRED}

Fifty six students (40\%) were able to read N5 to N8 print at presentation, either unaided (43) or with their own spectacles (13). All students able to see N8 at presentation (16) were able to read N5 after accurate refraction. Eight students (6\%) were able to discern $\mathrm{N} 10-\mathrm{N} 18$ print at presentation, which improved to N5-N8 with corrective lenses and 46 students who had near acuities of $\mathrm{N} 10$ or less at presentation were able to read N5-N8 with LVDs.

Twelve students could read N10-N36 print but the acuity could not be improved to N5-N8. Two of these students achieved N10-N36 with corrective lenses and three with LVDs. Five students could not be assessed with LVDs because they were too young, or because of inadequate comprehension or concentration.

Two students could discern N48 print, one with corrective lenses and one with an LVD. Overall, 27 students (19.3\%) needed new spectacles to achieve their best level of near vision and $50(35 \cdot 7 \%)$ needed LVDs.

\section{LEVEL OF MAGNIFICATION REQUIRED}

The dioptric power required has been calculated from the reciprocal of the reading distance of the better eye (Table 5). The mean dioptric power required by students in groups $1,2,4$, and 5 who did not require LVDs is lower than the dioptric power required by students in groups 3 and 6 who did need LVDs (range of means 11.25 D-14.8 D compared with 25.8 D$63 \mathrm{D})$. 
Table 5 Level of magnification required in 140 students with low vision in blind schools in Kenya and Uganda

\begin{tabular}{|c|c|c|c|c|c|}
\hline Group & Near $V A$ & Optical device & $N$ & $\begin{array}{l}\text { Mean } \\
\text { power (D) }\end{array}$ & $\begin{array}{l}\text { Range } \\
\text { (D) }\end{array}$ \\
\hline $\begin{array}{l}1 \\
2 \\
3\end{array}$ & N5-N8 & $\begin{array}{l} \pm \text { Own spectacles } \\
\text { With new correction } \\
\text { LVD } \pm \text { corrective lenses }\end{array}$ & $\begin{array}{r}56 \\
8 \\
46\end{array}$ & $\begin{array}{l}11 \cdot 4 \\
14 \cdot 8 \\
25 \cdot 8\end{array}$ & $\begin{array}{l}6-20 \\
6 \cdot 5-33 \\
6 \cdot 5-56\end{array}$ \\
\hline $\begin{array}{l}4 \\
5 \\
6\end{array}$ & N10-N18 & $\begin{array}{l} \pm \text { Own spectacles } \\
\text { With new correction } \\
\text { LVD } \pm \text { corrective lenses }\end{array}$ & $\begin{array}{l}7 \\
2 \\
3\end{array}$ & $\begin{array}{l}14 \cdot 1 \\
11 \cdot 25 \\
63 \cdot 0\end{array}$ & $\begin{array}{l}6 \cdot 5-33 \\
10-12 \cdot 5 \\
50-76\end{array}$ \\
\hline 7 & $\mathrm{~N} 48$ or less & & 18 & - & - \\
\hline
\end{tabular}

TYPE AND RANGE OF LOW VISION DEVICES REQUIRED

Of the 50 students requiring LVDs, 21 found stand magnifiers the easiest to use (range $+20 \mathrm{D}$ to $+76 \mathrm{D}$ ), a further 19 students benefited from high reading adds (range $+6 \mathrm{D}$ to $+20 \mathrm{D}$ ), and the remaining students used hand held magnifiers (+20 D) and hyperoculars (range $+24 \mathrm{D}$ to $+48 \mathrm{D}$ ). Nine students needed LVDs with powers in the range $+29 \mathrm{D}$ to $+40 \mathrm{D}$, and a further nine required more than $+40 \mathrm{D}$ (Table 6$)$.

\section{LOW VISION DEVICES PRODUCED BY}

CHRISTOFFEL BLINDENMISSION

Twenty two of the 50 students who benefited from the British LVDs were able to read the same size print with CBM LVDs of equivalent power (Table 7). Eleven students were able to read print of the same size but they needed CBM LVDs of higher power to achieve the same near acuity. In six students the level of near acuity achieved with the CBM LVDs was not as good as with the British LVDs. The range of magnification available in the CBM LVDs was not adequate for students with the lowest levels of vision where high power devices were needed. Overall the CBM LVDs were able to meet the need in $66 \%$ of students who would benefit from LVDs and in $72 \%$ of those students who could discern N5-N8 print.

IDENTIFICATION OF STUDENTS WHO HAVE THE POTENTIAL TO BENEFIT FROM LOW VISION SERVICES

There was a correlation between corrected distance acuity in the better eye and the level of near acuity achieved (Table 8). Only one of 18 students $(5 \cdot 6 \%)$ with less than $1 / 60$ corrected distance acuity was able to read N5-N8, compared with $60 \%$ with $1 / 60-2 / 60,96 \%$ with $3 / 60-5 / 60$, and $98 \%$ with $6 / 60$ or better.

Table 6 Range and type of British low vision devices required in 50 students with low vision

\begin{tabular}{|c|c|c|c|c|c|c|c|c|}
\hline \multicolumn{2}{|c|}{$\begin{array}{l}\text { Stand } \\
\text { magnifiers }\end{array}$} & \multicolumn{2}{|c|}{$\begin{array}{l}\text { High reading } \\
\text { add }\end{array}$} & \multicolumn{2}{|c|}{$\begin{array}{l}\text { Hand held } \\
\text { magnifier }\end{array}$} & \multirow[b]{2}{*}{ Mag } & \multicolumn{2}{|c|}{ Hyperocular } \\
\hline Power & $N$ & Power & $N$ & Power & $N$ & & Power & $N$ \\
\hline $\begin{array}{r}+20 \mathrm{D} \\
+28 \mathrm{D} \\
+36 \mathrm{D} \\
+44 \mathrm{D} \\
+56 \mathrm{D} \\
+76 \mathrm{D}\end{array}$ & $\begin{array}{l}3 \\
6 \\
4 \\
2 \\
4 \\
2\end{array}$ & $\begin{array}{r}+6 \mathrm{D} \\
+10 \mathrm{D} \\
+12 \mathrm{D} \\
+16 \mathrm{D} \\
+20 \mathrm{D}\end{array}$ & $\begin{array}{l}3 \\
7 \\
2 \\
5 \\
2\end{array}$ & $+20 \mathrm{D}$ & 2 & $\begin{array}{r}\times 6 \\
\times 8 \\
\times 10 \\
\times 12\end{array}$ & $\begin{array}{l}+24 \mathrm{D} \\
+32 \mathrm{D} \\
+40 \mathrm{D} \\
+48 \mathrm{D}\end{array}$ & $\begin{array}{l}2 \\
4 \\
1 \\
1\end{array}$ \\
\hline Total & 21 & & 19 & & 2 & & & 8 \\
\hline
\end{tabular}

Sixteen students who were blind according to WHO categories of visual loss (that is, $<3 / 60$ corrected acuity in the better eye) could read N5-N8 print with LVDs.

A corrected distance visual acuity $\geqslant 1 / 60$ identified students able to read N5-N8 print after low vision assessment with a sensitivity of $99 \cdot 1 \%$ and a specificity of $56 \cdot 7 \%$.

The results of the functional vision tests show that $95 \%$ of students who could discern N5-N8 print were able to perform at least two of the three tests of functional vision compared with $58 \%$ students able to discern N10-N36 print and $22 \%$ students able to read N48 or less (Table 9). The ability to perform two or all three tests of functional vision identified students able to read N5-N8 print after low vision assessment with a sensitivity of $95.9 \%$ and a specificity of $63 \cdot 3 \%$.

TYPE OF EDUCATION

Eighty of the 140 students (57\%) with low vision were being taught to read using braille only, even though $110(79 \%)$ had the potential to read N5-N8 print, and a further $9 \%$ had the potential to read N10-N36 print.

\section{Discussion}

The schools for the blind included in the study (two in Uganda and three in Kenya) varied enormously with respect to size, quality of buildings, infrastructure, availability of teaching materials, facilities for recreation, number of staff, and degree of integration of students into normal schools. In all the schools several of the teachers were themselves blind or visually impaired. Low vision services and LVDs were not available in any of the schools. In Kenya a peripatetic special educationalist has recently been appointed to promote educational techniques for students with low vision, and an orthoptist has been appointed to initiate low vision services. In two of the schools in the study students with residual vision were being taught to read ink print and were given instruction on tasks of daily living, but the emphasis in all the schools was on education using techniques appropriate to the totally blind - that is, braille. Although reasons for this were not investigated in this study there are several factors which may be responsible. Firstly, low vision services are a fairly recent development ${ }^{11}$ and teachers in special schools may find it difficult to adapt to the new concepts and to change their practices. Secondly, teachers may construe by implication that the methods they have used in the past were wrong. Thirdly, in many schools for the blind a significant proportion of the teachers are blind or visually impaired themselves and it would be difficult for them to change to sighted methods of teaching. Fourthly, few materials and facilities are available for low vision education. In this study $57 \%$ of students with low vision were being taught to read using braille only, even though $79 \%$ were capable of reading N5-N8 print. There is a need to improve awareness in 
Table 7 Effectiveness of locally produced CBM low vision devices compared with British standard low vision devices ( $L V D S$ )

\begin{tabular}{lllll}
\hline $\begin{array}{l}\text { Near visual acuity }(V A) \text { with } \\
\text { locally produced LVD }\end{array}$ & $\begin{array}{l}\text { Group 3 } \\
\text { (N5-N8) }\end{array}$ & $\begin{array}{l}\text { Group 6 } \\
\text { (N10-N36) }\end{array}$ & $\begin{array}{l}\text { Group 7 } \\
(\geqslant N 48)\end{array}$ & Total \\
\hline Same near VA with same power local LVD & 22 & 0 & 0 & 22 \\
Same near VA with higher power local LVD & 11 & 0 & 0 & 11 \\
Worse near VA & 6 & 0 & 0 & 6 \\
Local produced LVD of no benefit & 7 & 3 & 1 & 11 \\
Total & 46 & 3 & 1 & 50 \\
Needs met by locally produced LVD (\%) & 71.7 & 0 & 0 & 66.0 \\
\hline
\end{tabular}

parents and teachers involved in special education in developing countries, emphasising that children with low vision can and should use their residual vision wherever possible. There is also a need to provide appropriate low vision training, facilities, and educational materials for teachers and pupils.

\section{NEED FOR OPTICAL SERVICES}

More than half the students with low vision had spherical or astigmatic refractive errors of more than 2 dioptres. In 59 students the vision improved with spectacles and one third (46) of students required new spectacles. At least $20 \%$ of the total blind school population included in this study could benefit from new spectacles. Accurate refraction of children with high refractive errors often in association with media opacities is not easy and requires experience and patience. It is recommended that children with visual handicap in schools for the blind or in integrated education be refracted annually and spectacles made available to them at no or minimum cost.

\section{NEED FOR LOW VISION DEVICES}

More than a third of the students with low vision in this study (50/140) would benefit from LVDs. At assessment 46 of these students were able to read N5-N8 print. This performance might not be sustained for long periods but would allow access to most printed information. There was a wide range in the power of the devices required and different types of LVDs were needed. A smaller range of LVDs would not therefore meet all the need. Eighteen of the 50 students $(36 \%)$ needed LVDs of more than $+28 \mathrm{D}$. The CBM LVDs met the need in two thirds of the students who had the potential to benefit. However, in $22 \%$ of students higher powers were required with the CBM LVDs to achieve the same level of near vision as with the British devices, probably because the latter have superior optical qualities. Plastic, aspheric lenses, however, cannot be produced without sophisticated

Table 8 Corrected distance acuity in the better eye by level of near vision after low vision assessment in 140 students in Kenya and Uganda

\begin{tabular}{|c|c|c|c|c|c|c|c|c|}
\hline \multirow{2}{*}{$\begin{array}{l}\text { Corrected } \\
\text { distance acuity }\end{array}$} & \multicolumn{2}{|c|}{$N 5-N 8$} & \multicolumn{2}{|c|}{$N 10-N 36$} & \multicolumn{2}{|c|}{ N48 or less } & \multicolumn{2}{|c|}{ Total } \\
\hline & $N$ & $\%$ & $N$ & $\%$ & $N$ & $\%$ & $N$ & $\%$ \\
\hline $\begin{array}{l}<1 / 60 \\
1 / 60-2 / 60 \\
3 / 60-5 / 60 \\
6 / 60 \text { or better }\end{array}$ & $\begin{array}{r}1 \\
15 \\
46 \\
48\end{array}$ & $\begin{array}{r}5 \cdot 6 \\
60 \cdot 0 \\
95 \cdot 8 \\
98 \cdot 0\end{array}$ & $\begin{array}{l}3 \\
6 \\
2 \\
1\end{array}$ & $\begin{array}{r}16 \cdot 7 \\
24 \cdot 0 \\
4 \cdot 2 \\
2 \cdot 0\end{array}$ & $\begin{array}{r}14 \\
4 \\
0 \\
0\end{array}$ & $\begin{array}{c}77 \cdot 7 \\
16 \cdot 0 \\
0 \\
0\end{array}$ & $\begin{array}{l}18 \\
25 \\
48 \\
49\end{array}$ & $\begin{array}{l}100 \\
100 \\
100 \\
100\end{array}$ \\
\hline Total & 110 & $78 \cdot 6$ & 12 & $8 \cdot 6$ & 18 & $12 \cdot 9$ & 140 & \\
\hline
\end{tabular}

manufacturing facilities. It is relatively easy to purchase or grind glass lenses with powers of up to $+28 \mathrm{D}$, but lenses of higher power are not readily available and are far more difficult to produce. This will limit the range of LVDs that can be produced locally given the present technology. The LVDs being produced by the CBM optical workshop in Nairobi cost approximately $£ 2.50$ each to produce.

There is debate whether schools for the blind in developing countries should use enlarging photocopiers to produce educational materials for students with low vision. These machines are expensive to purchase and run, depend on electricity, need regular supplies of paper of good quality and standard size, and continued maintenance particularly in hot, dusty climates. The findings of this study suggest that accurate correction of refractive errors and provision of appropriate LVDs for near vision would provide a flexible, cost effective, and sustainable alternative.

\section{SIMPLE METHODS OF IDENTIFYING STUDENTS} WITH LOW VISION WHO WOULD BENEFIT FROM LOW VISION ASSESSMENT

Low vision services are in their infancy in most developing countries, and ophthalmic and optical services scarce. To maximise resources there is a need to develop simple methods and guidelines which could be used by those responsible for children with visual impairment to identify those who should be referred for low vision assessment. In this study the majority of students (14/18) with a corrected distance visual acuity of less than $1 / 60$ to perception of light could not read print of any size, suggesting that form vision is required before students can benefit from LVDs. However, $38 \%$ of students with a corrected distance acuity of less than $1 / 60$ had sufficient vision to perform one or more of the simple tests of functional vision, suggesting that form vision is not a prerequisite for independent mobility and social contact.

The ability to see $1 / 60$ or more after full distance correction could be used to identify those students who will benefit from low vision devices (sensitivity 99\%). If full refraction services are not available, teachers could be taught to assess students using the three simple tests of functional which had a sensitivity of $96 \%$ in identifying students who could read N5-N8 print.

\section{SERVICE PROVISION IMPLICATIONS}

In this study assessment was undertaken in classrooms and seven students could not be assessed for LVDs because of additional handicap, or because they were too young. As considerable motivation, manual dexterity, time, enthusiasm, and concentration are required on the part of the child as well as the optometrist during low vision assessment, this should be undertaken in a conducive environment.

For low vision devices to be used effectively support, training, follow up, and maintenance are needed, particularly for younger children 712 
Table 9 Results of tests of functional vision in 140 students with low vision in Kenya and Uganda

\begin{tabular}{|c|c|c|c|c|c|c|c|c|c|}
\hline \multirow[b]{2}{*}{ Near vision } & \multirow[b]{2}{*}{ Total } & \multicolumn{2}{|c|}{$\begin{array}{l}\text { Failed all } \\
\text { three tests }\end{array}$} & \multicolumn{2}{|c|}{$\begin{array}{l}\text { Performed } \\
\text { one test }\end{array}$} & \multicolumn{2}{|c|}{$\begin{array}{l}\text { Performed } \\
\text { two tests }\end{array}$} & \multicolumn{2}{|c|}{$\begin{array}{l}\text { Performed all } \\
\text { three tests }\end{array}$} \\
\hline & & $N$ & $\%$ & $N$ & $\%$ & $N$ & $\%$ & $N$ & $\%$ \\
\hline $\begin{array}{l}\text { N5-N8 } \\
\text { N10-N36 } \\
\text { N48 or less }\end{array}$ & $\begin{array}{r}110 \\
12 \\
18\end{array}$ & $\begin{array}{r}5 \\
2 \\
11\end{array}$ & $\begin{array}{r}4 \cdot 5 \\
16 \cdot 7 \\
61 \cdot 1\end{array}$ & $\begin{array}{l}0 \\
3 \\
3\end{array}$ & $\begin{array}{c}0 \\
25 \cdot 0 \\
16 \cdot 7\end{array}$ & $\begin{array}{r}12 \\
1 \\
2\end{array}$ & $\begin{array}{r}10 \cdot 9 \\
8 \cdot 3 \\
11 \cdot 1\end{array}$ & $\begin{array}{r}93 \\
6 \\
2\end{array}$ & $\begin{array}{l}84 \cdot 5 \\
50 \cdot 0 \\
11 \cdot 1\end{array}$ \\
\hline Total & 140 & 18 & 12.9 & 6 & $4 \cdot 3$ & 15 & $10 \cdot 7$ & 101 & $72 \cdot 1$ \\
\hline
\end{tabular}

and those with lower levels of acuity. In addition many students will need to be re-educated as 'sighted' rather than 'blind'. With high power devices more supervised practice will be required, and greater motivation on the part of the user.

For low vision services to become widely available to children with low vision in developing countries there is a need to (1) develop simple guidelines for identifying students with low vision who require assessment, (2) define the level of training required to undertake low vision assessment, (3) develop simplified methods of assessing students with low vision which can be used by 'non-experts', as well as guidelines on prescribing, (4) develop simple guidelines on training in the use and maintenance of LVDs, (5) modify and promote the production of locally produced LVDs.
To provide sustainable, low cost, low vision services close cooperation between optometrists, optical technicians, ophthalmologists, teachers, and parents will be essential.

We are grateful to Combined Optical Industries, who donated sets of low vision devices for the assessments; to Keeler, who donated Sonksen-Silver acuity cards; and to the staff and donated Sonksen-Silver acuity cards; and to the staff and
students at the schools. The study was funded by the Peel Medical Trust, 'Help a Child See', Christoffel Blindenmission, Germany, and Sight Savers, UK.

1 The management of low vision of childhood. Proceedings of WHO/PBL Consultation Bangkok, July 1992. Geneva: WHO, 1993.

2 Fagan T, Kenya: African report. $\mathcal{f}$ Vis Imp Blindness 1992 86: 16

3 Spoerer P. How to make spectacles at low cost. Bensheim, Germany: Christoffel Blindenmission, 1994: 161-71.

4 British Standard No 7522, 1992. Part 1: Hand and stand magnifiers. London: British Standards Institution.

5 Jalie M. The principals of ophthalmic lenses. Vol III. London: Association of Dispensing Opticians, 1969: 546-56.

6 Bennett AG. Ophthalmic test types. Br $¥$ Phys Optics 1965; 22: 238 .

7 Nott J. The use of low vision aids by children under the age of seven years. $B r F$ Vis Imp 1994; 12: 57-9.

8 Bullimore M, Bailey I. Evaluation of new optical aids from COIL. Optometry Vis Sci 1989; 66: 766-73.

9 Leat S, Rumney N. Modulation transfer function of low vision aids. Applied Optics 1992; 31: 3637-45.

10 Gilbert C, Foster A, Negrel D, Thylefors B. Childhood blindness: a new form for recording causes of visual loss in children. WHO Bull 1993; 71: 485-9.

11 Silver J. The place of optimum low vision aids in the management of visual handicap. MPhil Thesis, City University, 1976.

12 Leat $S$, Karadsheh $S$. Use and non-use of low vision aids by visually impaired children. Ophthal Physiol Opt 1991; 11: $10-21$ 